\title{
Modeling an industrial sodium bicarbonate bubble column reactor
}

\author{
Ataallah Soltani Goharrizi • Bahador Abolpour
}

Received: 18 September 2013/ Accepted: 9 June 2014/Published online: 4 July 2014

(c) The Author(s) 2014. This article is published with open access at Springerlink.com

\begin{abstract}
This paper deals with the study of the gasliquid mass transfer, coupled with chemical reactions, the gas-liquid-solid mass transfer, and crystallization. Sodium bicarbonate is produced in a bubble column reactor which contains a solution of carbonate and bicarbonate and carbon dioxide gas injected into this column. In this mathematical modeling, a mole balance has been instituted on flows and components through the bubble column. A population balance is utilized to obtain the nucleation and growth formula for the solid phase. Danckwerts theory is utilized for mass transfer between gas and liquid phases. This model can predict the effects of several parameters on the production and size distribution of sodium bicarbonate crystals and also conversion of carbon dioxide. The mathematic simulator model results are compared with the experimental results to valid this model. Effects of different parameters on the production and size distribution of sodium bicarbonate crystals and also absorbent of carbon dioxide are investigated.
\end{abstract}

Keywords Sodium bicarbonate $\cdot$ Bubble column - Triple phase mass transfer $\cdot$ Crystallization $\cdot$ Modeling

\section{List of symbols}

$\begin{array}{ll}a & \text { Growth rate coefficient } \\ b & \text { Growth order }(\mathrm{g}) \\ B_{0} & \text { Nucleation (\#/s kg solution) } \\ C_{\mathrm{CO}_{2} e} & \text { Carbon dioxide concentration in liquid bulk } \\ & \left(\mathrm{mol} / \mathrm{m}^{3}\right)\end{array}$

A. S. Goharrizi · B. Abolpour $(\bowtie)$

Department of Chemical Engineering, Faculty of Engineering,

Shahid Bahonar University of Kerman, Jomhoori Blvd,

76175 Kerman, Iran

e-mail: bahadorabolpor1364@yahoo.com $c$

$\mathrm{C}_{\mathrm{CO}_{2} i}$

$d$

$d_{B}$

$D_{\mathrm{CO}_{2}}$

$D_{\mathrm{g}}$

$D_{1}$

$d_{R}$

E

e

$g$

G

$G_{0}$

$G_{\mathrm{FR}}$

h

H

I

$I_{0}$

$k$

$K_{1}$

L

$L_{\text {FR }}$

$L_{n u}$

$M_{T}$

N

$n$

$n_{\text {Dis }}$

no

$P_{0}$

$P_{\mathrm{CO}_{2}}$
Nucleation rate coefficient

Carbon dioxide concentration in gas-liquid interface $\left(\mathrm{mol} / \mathrm{m}^{3}\right)$

Magma density order

Average of bubbles diameter (m)

Carbon dioxide molecular diffusion coefficient $\left(\mathrm{m}^{2} / \mathrm{s}\right)$

Gas phase radial dispersion coefficient $\left(\mathrm{m}^{2} / \mathrm{s}\right)$

Liquid phase radial dispersion coefficient $\left(\mathrm{m}^{2} / \mathrm{s}\right)$

Column diameter (m)

Enhancement factor

Nucleation order

Gravity $\left(\mathrm{m} / \mathrm{s}^{2}\right)$

Molar velocity of gas $\left(\mathrm{mol} / \mathrm{m}^{2} \mathrm{~s}\right)$

Growth rate $(\mu \mathrm{m} / \mathrm{s})$

Gas flow rate $\left(\mathrm{m}^{3} / \mathrm{s}\right)$

Column height $(\mathrm{m})$

Henry constant $\left(\mathrm{Kmol} / \mathrm{atm} \mathrm{m}^{3}\right.$ )

Ionic content of solution $\left(\mathrm{kg}\right.$ ion $\left./ \mathrm{m}^{3}\right)$

Height of column that sodium bicarbonate reachs to saturation concentration

Constant rate of first order reaction $(1 / \mathrm{s})$

Liquid phase mass transfer coefficient $(\mathrm{m} / \mathrm{s})$

Molar velocity of liquid $\left(\mathrm{mol} / \mathrm{m}^{2} \mathrm{~s}\right)$

Liquid mass flow rate $(\mathrm{kg} / \mathrm{s})$

Size of crystals $(\mu \mathrm{m})$

Magma density (g crystal/kg solution)

Flux of mass transfer $\left(\mathrm{mol} / \mathrm{m}^{2} \mathrm{~s}\right)$

Population density (no./ $\mu \mathrm{m} \mathrm{kg}$ solution)

Flux of mass transfer by dispersion $\left(\mathrm{mol} / \mathrm{m}^{2} \mathrm{~s}\right)$

Number of nucleons that born at $\mathrm{d} z$

Gas pressure at bottom of column (atm)

Carbon dioxide partial pressure at gas phase (atm)

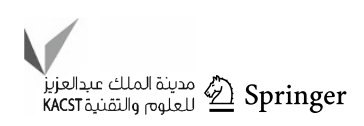


$P_{\mathrm{CO}_{2} e} \quad$ Carbon dioxide partial pressure at liquid bulk (atm)

$P_{\mathrm{CO}_{2} i} \quad$ Carbon dioxide partial pressure at gas-liquid interface (atm)

$Q \quad$ Liquid flow rate $\left(\mathrm{m}^{3} / \mathrm{s}\right)$

$r \quad$ Rise of nucleons from $\mathrm{d} z$ to bottom of the column $\left(\mathrm{m}^{3}\right)$

$R \quad$ Gases constant $(\mathrm{J} / \mathrm{g} \mathrm{mol} \mathrm{K})$

$S \quad$ Molar velocity of solid $\left(\mathrm{mol} / \mathrm{m}^{2} \mathrm{~s}\right)$

$T \quad$ Liquid temperature $(\mathrm{K})$

$t \quad$ Time

$U_{\mathrm{g}} \quad$ Gas phase velocity $(\mathrm{m} / \mathrm{s})$

$U_{1} \quad$ Liquid phase velocity $(\mathrm{m} / \mathrm{s})$

$V \quad$ Volume of element $\left(\mathrm{m}^{3}\right)$

$w \quad$ Weight fraction of component in liquid phase

$\Delta w \quad$ Supersaturation ( $\mathrm{g} \mathrm{NaHCO}_{3} / \mathrm{kg}$ solution)

$x \quad$ Mole fraction of components in liquid phase

$x_{\mathrm{NaHCO}_{3}}^{*}$ Mole fraction of sodium bicarbonate at supersaturation

$y \quad$ Mole fraction of components in gas phase

$z \quad$ Height of column (m)

\section{Greek symbols}

$\alpha_{\mathrm{g}} \quad$ Gas-liquid interface $\left(\mathrm{m}^{2} / \mathrm{m}^{3}\right)$

$\alpha_{\mathrm{s}} \quad$ Solid-liquid interface $\left(\mathrm{m}^{2} / \mathrm{m}^{3}\right)$

$\delta \quad$ Liquid surface tension $(\mathrm{N} / \mathrm{m})$

$\varepsilon_{\mathrm{g}} \quad$ Gas holdup

$\varepsilon_{1} \quad$ Liquid holdup

$\mu_{j} \quad$ jth moment of population density

$\mu_{1} \quad$ Liquid dynamic viscosity $\left(\mathrm{N} \mathrm{s} / \mathrm{m}^{2}\right)$

$\rho_{\mathrm{H}_{2} \mathrm{O}} \quad$ Water density $\left(\mathrm{kg} / \mathrm{m}^{3}\right)$

$\rho_{1} \quad$ Liquid density $\left(\mathrm{kg} / \mathrm{m}^{3}\right)$

$v_{1} \quad$ Liquid kinematic viscosity $\left(\mathrm{m}^{2} / \mathrm{s}\right)$

\section{Subscripts}

$i \quad$ At inlet point position of element

$I_{0} \quad$ At $I_{0}$ point position

in At inlet point position of column

$o \quad$ At outlet point position of element

\section{Introduction}

Sodium bicarbonate crystals have a low solubility in water. These crystals decompose to carbonate and carbon dioxide at a temperature of more than $60{ }^{\circ} \mathrm{C}$. Bubble column reactors are used to produce sodium bicarbonate. These columns have high rate of mass transfer, small volumes, and low costs of operation. Industrial crystallization processes involve a large number of complex physical and chemical phenomena. To control the quality of the product, it is essential to understand the role of each parameter in the nucleation and growth processes.
Absorbance of carbon dioxide in a solution of sodium bicarbonate and sodium carbonate, in a lab scale has been simulated by Ref. [1]. Those experimentations were done in different temperatures and catalyst concentrations and the rate of gas-liquid interface changes, liquid mass transfer coefficient, and reaction constant rate were computed using Danckwerts model [2]. Comparing experimental and model results, they concluded that gas film resistance has no effect on mass transfer and can be neglected. The sodium bicarbonate settlement process in industrial scale bubble columns is investigated by Ref. [3]. They used computational fluids dynamic's method and compared results with operating data.

Estimation of sodium bicarbonate crystal size distributions of such bubble column reactors is presented in the previous study [4]. Using a constant nucleation and growth rate of sodium bicarbonate crystals $\left(B_{0}=26.685 \times M_{T}^{0.42} \times \Delta w^{1.3}\right.$, $G_{0}=1.381 \times 10^{-4} \Delta w^{1.53}$ that experimentally were calculated by Saberi et al. [5], at an unsteady-state condition) in different operating condition decreased the accuracy of model results. The main purpose of the present study is modeling and simulating sodium bicarbonate production process in bubble columns reactors. Flow in these reactors is three phase (solid, liquid and gas) and conjugated with a set of chemical reactions. Therefore, the respective model is based on the threephase mass balance, Danckwerts theory for mass transfer from gas phase to liquid, absorbance of $\mathrm{CO}_{2}$ with mass transfer and chemical reaction. This mathematical model can predict the effects of several parameters (i.e. liquid temperature, gas pressure, and mole fraction of carbon dioxide in gas phase) on the production and size distribution of sodium bicarbonate crystals, and also conversion of carbon dioxide.

In this research, the production and size distribution of sodium bicarbonate crystals, and conversion of carbon dioxide in the bubble column reactor of Shiraz Petrochemical Complex are studied. This study contains a triplephase modeling to simulate the operation of this bubble column. In this model, mole and population balances are utilized to obtain the nucleation and growth formula for the solid phase. This is a novel method to obtain the nucleation and growth rates of produced sodium bicarbonate crystals in different operating conditions. It must be noted that, the production of sodium bicarbonate crystals in this bubble column is a complex operation and simulation of this phenomenon can be used to optimize the production and size distribution of these crystals.

\section{Process description}

The process of sodium bicarbonate producing is shown in Fig. 1. This bubble column has the inner diameter of $1.2 \mathrm{~m}$ 


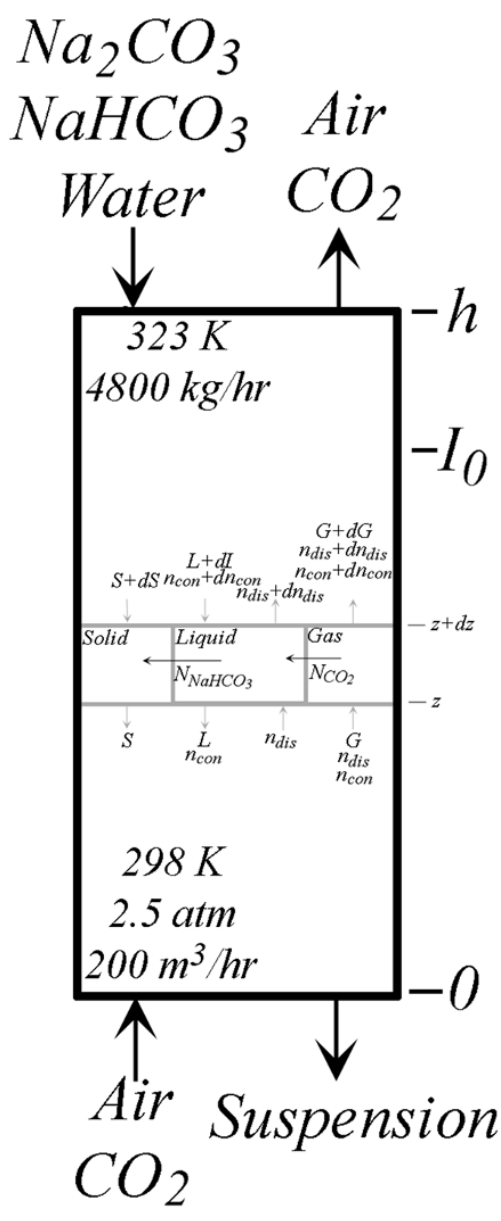

Fig. 1 Production of sodium bicarbonate in bubble column

with the height of $22 \mathrm{~m}$. The temperature of operation is assumed to be constant in the length of column due to low heat of reaction and using of a water jacket around it. The solution contains water, sodium carbonate and sodium bicarbonate. This solution enters the column from its upper side and a gaseous mixture of carbon dioxide and air is continuously injected to the column from its bottom. The following equilibrium reactions can be established in the column:

$\mathrm{CO}_{2}(g) \leftrightarrow \mathrm{CO}_{2}(l)$

$\mathrm{CO}_{2}(l)+\mathrm{OH} \leftrightarrow \mathrm{HCO}_{3}$

$\mathrm{HCO}_{3}^{-}+\mathrm{OH}^{-} \leftrightarrow \mathrm{CO}_{3}^{2-}+\mathrm{H}_{2} \mathrm{O}$

$\mathrm{Na}^{+}+\mathrm{HCO}_{3}^{-} \rightarrow \mathrm{NaHCO}_{3}$

When the concentration of produced sodium bicarbonate reaches its solubility limit in the solution (solution becomes saturated from sodium bicarbonate), reaction (4) takes place and the crystals begin to form in the column [6]. The column operating conditions is shown in Fig. 1. The solubility of $\mathrm{NaHCO}_{3}$ in the presence of $\mathrm{Na}_{2} \mathrm{CO}_{3}$ is given in the Ref. [7] as below: $\log \left(x^{*}\right)=6.71535-\frac{843.0681}{T}-2.24336 \times \log (T)$.

\section{Model formulation}

The governing and mass transfer equations are obtained using a one-dimensional differential control volume in the length of reactor, as shown in Fig. 1. Since there exists a rotational flow in this column, a radial dispersion model is applied to model the gas and liquid phases. Reference [8] used a circulation cell to study a mixing process.

Flux of carbon dioxide from gas to liquid phase and flux of sodium bicarbonate from liquid to solid phase affect the sodium bicarbonate concentration in the liquid phase. Therefore, the quantity of supersaturation is a function of these fluxes in the bubble column.

Gas phase mole balance

A mole balance for gas phase around the element yields the following differential governing equation:

$\frac{\mathrm{d} G}{\mathrm{~d} z}=-N_{\mathrm{CO}_{2}} \times \alpha_{\mathrm{g}}$

that:

$\alpha_{\mathrm{g}}=\frac{6 \times \varepsilon_{\mathrm{g}}}{d_{\mathrm{B}}}$

and mole balance for carbon dioxide results in the following differential equation:

$\frac{\mathrm{d}}{\mathrm{d} z}\left(G \times y_{\mathrm{CO}_{2}}\right)-\frac{\varepsilon_{\mathrm{g}} \cdot D_{\mathrm{g}}}{U_{\mathrm{g}}} \times \frac{d^{2}}{\mathrm{~d} z^{2}}\left(G \times y_{\mathrm{CO}_{2}}\right)=-N_{\mathrm{CO}_{2}} \times \alpha_{\mathrm{g}}$

that gas velocity is given by:

$U_{\mathrm{g}}=\frac{4 \times G_{\mathrm{FR}}}{\pi \cdot d_{R}^{2} \cdot \varepsilon_{\mathrm{g}}}$

It is assumed that gas velocity is constant in the column. The first and second terms of this equation are derived from fluid bulk motion and radial dispersion in gas phase (that is raised from bubbles motions with different velocities), respectively.

Liquid phase mole balance

The column is divided by two zones. The first is from top to a point that sodium bicarbonate achieves to saturation concentration $\left(I_{0}\right.$ height in Fig. 1$)$, and the second is from this point to bottom. Inlet solution has a saturation concentration of sodium bicarbonate, at operating conditions illustrated in Fig. 1. Therefore, crystallization occurs in the whole length of the 
column, and the produced sodium bicarbonate goes to solid phase. If inlet solution has a saturation or supersaturation concentration of sodium bicarbonate, the first zone will be removed and the second zone covers the entire column $\left(I_{0}=0\right)$. The reaction of sodium bicarbonate production is a fast reaction in high temperatures. Therefore, it is assumed that the rate of carbon dioxide consumption reaction be equal with its absorbency rate. Therefore, the molar velocity of liquid phase and components is calculated using carbon dioxide absorbance and reaction stoichiometry.

Mole balance in the first zone (which has no solid) can be written in the following form:

$\frac{\mathrm{d} L}{\mathrm{~d} z}=0$

Mole balance for sodium carbonate, sodium bicarbonate, and water in this zone can be written in the following forms:

$\frac{\varepsilon_{1} \cdot D_{1}}{U_{1}} \times L \times \frac{\mathrm{d}^{2}}{\mathrm{~d} z^{2}}\left(x_{\mathrm{Na}_{2} \mathrm{CO}_{3}}\right)+L \times \frac{\mathrm{d}}{\mathrm{d} z}\left(x_{\mathrm{Na}_{2} \mathrm{CO}_{3}}\right)=N_{\mathrm{CO}_{2}} \times \alpha_{\mathrm{g}}$

$\frac{\varepsilon_{1} \cdot D_{1}}{U_{1}} \times L \times \frac{\mathrm{d}^{2}}{\mathrm{~d} z^{2}}\left(x_{\mathrm{NaHCO}_{3}}\right)+L \times \frac{\mathrm{d}}{\mathrm{d} z}\left(x_{\mathrm{NaHCO}_{3}}\right)$

$=-2 \times N_{\mathrm{CO}_{2}} \times \alpha_{\mathrm{g}}$

$\frac{\varepsilon_{1} \cdot D_{1}}{U_{1}} \times L \times \frac{\mathrm{d}^{2}}{\mathrm{~d} z^{2}}\left(x_{\mathrm{H}_{2} \mathrm{O}}\right)+L \times \frac{\mathrm{d}}{\mathrm{d} z}\left(x_{\mathrm{H}_{2} \mathrm{O}}\right)=N_{\mathrm{CO}_{2}} \times \alpha_{\mathrm{g}}$

Mole balance in the second zone (that produced sodium bicarbonate is inserted to solid phase) can be written as the following differential equation:

$\frac{\mathrm{d} L}{\mathrm{~d} z}=N_{\mathrm{NaHCO}_{3}} \times \alpha_{s}$

and for each component we have:

$\frac{\varepsilon_{1} \cdot D_{1}}{U_{1}} \times \frac{\mathrm{d}^{2}}{\mathrm{~d} z^{2}}\left(L \times x_{\mathrm{Na}_{2} \mathrm{CO}_{3}}\right)+\frac{\mathrm{d}}{\mathrm{d} z}\left(L \times x_{\mathrm{Na}_{2} \mathrm{CO}_{3}}\right)=N_{\mathrm{CO}_{2}} \times \alpha_{\mathrm{g}}$

$\frac{\varepsilon_{1} \cdot D_{1}}{U_{1}} \times \frac{\mathrm{d}^{2}}{\mathrm{~d} z^{2}}\left(L \times x_{\mathrm{NaHCO}_{3}}\right)+\frac{\mathrm{d}}{\mathrm{d} z}\left(L \times x_{\mathrm{NaHCO}_{3}}\right)$

$=N_{\mathrm{NaHCO}_{3}} \times \alpha_{\mathrm{s}}-2 \times N_{\mathrm{CO}_{2}} \times \alpha_{\mathrm{g}}$

$\frac{\varepsilon_{1} \cdot D_{1}}{U_{1}} \times \frac{\mathrm{d}^{2}}{\mathrm{~d} z^{2}}\left(L \times x_{\mathrm{H}_{2} \mathrm{O}}\right)+\frac{\mathrm{d}}{\mathrm{d} z}\left(L \times x_{\mathrm{H}_{2} \mathrm{O}}\right)=N_{\mathrm{CO}_{2}} \times \alpha_{\mathrm{g}}$.

The first and second terms of recent equations are derived from the radial dispersion in liquid phase (that is raised from the motion of water by bubbles motion) and fluid bulk motion, respectively. The velocity of liquid is given with the following equation:
$U_{1}=\frac{4 \times L_{\mathrm{FR}}}{\pi \cdot d_{R}^{2} \cdot \varepsilon_{1} \cdot \rho_{1}}$

Solid phase mole balance

The first zone of the column produces no solid, therefore: $S=0$.

The produced sodium bicarbonate in the second zone is inserted to the solid phase. Therefore we have:

$\frac{\mathrm{d} S}{\mathrm{~d} z}=-N_{\mathrm{NaHCO}_{3}} \times \alpha_{s}$.

It is assumed that crystals have a same velocity as the liquid flow. Then, the number of nucleons that born at an element, rising of nucleons from an element to the bottom of column and molar velocity of solid are given by the following equations, respectively:

no $=\frac{B_{0} \cdot \rho_{1} \cdot \pi \cdot d_{R}^{2} \cdot(\mathrm{d} z)}{4}$

$r=\frac{\pi}{6}\left[\frac{G \times 10^{-6}}{U_{1}} \times(h-z)\right]^{3}$

$S=\frac{4 \times \rho_{\mathrm{s}}}{\pi \cdot d_{R}^{2} \cdot M_{\mathrm{s}}} \times\left[\sum(\right.$ no $\left.\times r)\right]$.

The boundary conditions of the bubble column can be written as below:

$\begin{aligned} \frac{\mathrm{d}}{\mathrm{d} z}\left(x_{\mathrm{Na}_{2} \mathrm{CO}_{3}}\right) & =0, \quad \frac{\mathrm{d}}{\mathrm{d} z}\left(x_{\mathrm{NaHCO}_{3}}\right)=0, \\ \frac{\mathrm{d}}{\mathrm{d} z}\left(x_{\mathrm{H}_{2} \mathrm{O}}\right) & =0, G=G_{\mathrm{in}}, \quad y_{\mathrm{CO}_{2}}=y_{\mathrm{CO}_{2} \text { in }} \text { at } z=0\end{aligned}$

$x_{\mathrm{Na}_{2} \mathrm{CO}_{3}}=x_{\mathrm{Na}_{2} \mathrm{CO}_{3} I_{0}}, x_{\mathrm{H}_{2} \mathrm{O}}=x_{\mathrm{H}_{2} \mathrm{OI}}, x_{\mathrm{NaHCO}_{3}}=x *{ }_{\mathrm{NaHCO}_{3}}, L$ $=L_{I_{0}}, S=0 \quad$ at $z=I_{0}$

$$
\begin{aligned}
& x_{\mathrm{Na}_{2} \mathrm{CO}_{3}}=x_{\mathrm{Na}_{2} \mathrm{CO}_{3} \mathrm{in}}, x_{\mathrm{NaHCO}_{3}} \\
& =x_{\mathrm{NaHCO}_{3} \text { in }}, x_{\mathrm{H}_{2} \mathrm{O}}=x_{\mathrm{H}_{2} \mathrm{Oin}}, \frac{\mathrm{d}}{\mathrm{d} z}\left(G \times y_{\mathrm{CO}_{2}}\right) \\
& =0, L=L_{\text {in }} \quad \text { at } \quad z=h .
\end{aligned}
$$

It is necessary to obtain pressure distribution to describe the volume fractions of components in the gas phase. The pressure distribution in bubble column is calculated by the following simple linear equation:

$P(z)=P_{0}-\rho_{1} \times\left(1-\varepsilon_{\mathrm{g}}\right) \times z$

Danckwerts obtained carbon dioxide absorbance rate using investigation of mass transfer with chemical reaction as the following equation: 
$N_{\mathrm{CO}_{2}}=E \times K_{1} \times\left(C_{\mathrm{CO}_{2} i}-C_{\mathrm{CO}_{2} e}\right)$

where $E$ calculates mass transfer coefficient with chemical reaction and can be obtained from the following relationship:

$E=\sqrt{1+\frac{D_{\mathrm{CO}_{2}} \cdot k}{K_{1}^{2}}}$

By attention to the carbon dioxide physical absorbance in the solution, its absorbance rate is defined as follow:

$N_{\mathrm{CO}_{2}}=E \times H \times K_{1} \times\left(P_{\mathrm{CO}_{2} i}-P_{\mathrm{CO}_{2} e}\right)$

The gas phase resistance can be ignored by attention to the circulation in bubbles and high gas mixing in this column. Therefore:

$N_{\mathrm{CO}_{2}}=E \times H \times K_{1} \times\left(P_{\mathrm{CO}_{2}}-P_{\mathrm{CO}_{2} e}\right)$.

The carbon dioxide partial pressure also can be ignored in liquid bulk, because carbon dioxide reacts with the sodium carbonate in liquid phase, rapidly. Therefore, carbon dioxide concentration in liquid phase is very low [9].

Reference [5] used an industrial scale bubble column scrubber to absorb simulated carbon dioxide gas and obtained precipitation kinetics. Precipitates of sodium bicarbonate were occurred using sodium bicarbonate and sodium carbonate solution as an absorbent to react with the carbon dioxide gas in the scrubber under an aqueous solution condition. Measured crystal size distributions at certain times were used to calculate the nucleation and growth rate of sodium bicarbonate crystals, which is proportional to an experimental nucleation and growth rate equation. But, these equations were gotten at unsteady-state operating conditions of bubble column. Those cannot be utilized at steady-state operating conditions. A population balance was used to determine the crystallization kinetic and obtain the value of growth and nucleation rate parameters. An empirical power law form is assumed for the growth rate:

$G_{0}=a \times \Delta w^{b}$.

The nucleation rate is considered as:

$B_{0}=c \times M_{T}^{d} \times \Delta w^{e}$.

Population balance equation for the crystallizer is defined as the following equation [10]:

$\frac{\partial n\left(L_{n u}, t\right)}{\partial t}+\frac{\partial\left(G_{0}\left(L_{n u}, t\right) \cdot n(L, t)\right)}{\partial L_{n u}}=-\sum_{k} \frac{n_{k}\left(L_{n u}, t\right) \cdot Q_{k}}{V}$.

In this equation, it is assumed that, agglomeration is negligible (which is also confirmed by Saberi et al. experimental data [5]). It is assumed that the growth rate of crystals is independent of their size. This assumption simplifies upper equation for each steady-state element as follow:

$G_{0} \times \frac{\partial n}{\partial L_{n u}}=\sum \frac{n_{\mathrm{o}} \cdot Q_{\mathrm{o}}}{V}-\sum \frac{n_{i} \cdot Q_{i}}{V}$.

Reference [11] describes determination of growth and nucleation rate by moment transformation of the population balance as below. The $j$ th moment of the population density with respect to crystal size is defined as:

$\mu_{j}=\int_{0}^{\infty} L_{n u}^{j} \times n \times d L_{n u}$.

Applying moment transformation on (33), and use $B_{0}=n(0) \times G_{0}$ results:

Table 1 The hydrodynamics and mass transfer parameters in bubble column

\begin{tabular}{|c|c|c|}
\hline Parameter & Equation & Reference \\
\hline$\varepsilon_{\mathrm{g}}$ & $\frac{\varepsilon_{g}}{\left(1-\varepsilon_{g}\right)^{4}}=0.2 \times\left(\frac{9.8 \times d_{R} \cdot \rho_{1}}{\delta}\right)^{\frac{1}{8}} \times\left(\frac{g \cdot d_{R}^{2} \cdot \rho_{l}^{2}}{\mu_{l}^{2}}\right)^{\frac{1}{12}} \times\left(\frac{U_{g}}{\sqrt{d_{R} \cdot g}}\right)$ & [12] \\
\hline$D_{\mathrm{g}}$ & $D_{\mathrm{g}}=5 \times d_{R} \times \frac{U_{\mathrm{g}}}{\varepsilon_{\mathrm{g}}}$ & [13] \\
\hline$D_{1}$ & $D_{1}=2.7 \times d_{R}^{1.4} \times\left(0.219 \times U_{\mathrm{g}}^{0.77}+0.122 \times U_{\mathrm{g}}^{0.1}\right)$ & [14] \\
\hline$K_{1}$ & $K_{1} \times \alpha_{\mathrm{g}}=0.6 \times \frac{D_{\mathrm{Co} 2}}{d_{R}} \times\left(\frac{\mu_{1}}{D_{1} \cdot \rho_{1}}\right)^{0.5} \times\left(\frac{g \cdot \rho_{1}}{\delta}\right)^{0.62} \times\left(\frac{g}{\left(\mu \mu_{l} \rho_{l}\right)^{2}}\right)^{0.31} \times \varepsilon_{\mathrm{g}}^{1.1}$ & [15] \\
\hline$H$ & $\log \left(H / H_{\mathrm{w}}\right)=-K_{\mathrm{s}} \times I ; \quad K_{\mathrm{s}}=0.06, I=6.2$ & [16] \\
\hline$H_{\mathrm{w}}$ & $\log \left(H_{\mathrm{w}}\right)=\frac{1,140}{T}-5.3$ & {$[16]$} \\
\hline$d_{\mathrm{B}}$ & $d_{\mathrm{B}}=26 \times d_{R} \times\left(\frac{g \cdot d_{R}^{2} \cdot \rho_{1}}{\delta}\right)^{-0.5} \times\left(\frac{g \cdot D_{1}^{3}}{v_{1}^{2}}\right)^{-0.12} \times\left(\frac{U_{g}}{\sqrt{g \cdot d_{R}}}\right)^{-0.12}$ & [15] \\
\hline$D_{\mathrm{CO}_{2}}$ & $D_{\mathrm{CO}_{2}}=5.35 \times 10^{-0.12} \times \frac{T}{\left(\mu_{l} / 10^{-3}\right)^{1.035}} \quad(47)$ & [17] \\
\hline$k$ & $k=\left[2.2 \times 10^{7} \times \exp \left(-\frac{71,500}{R \cdot T}\right)\right]-\left[3.2 \times 10^{-6} \times \rho_{\mathrm{H}_{2} \mathrm{O}} \times \exp \left(-\frac{13,800}{R \cdot T}\right)\right]$ & {$[18]$} \\
\hline
\end{tabular}


$j \times G_{0} \times \mu_{j-1}+(0)^{j} \times B_{0}=\sum \frac{\mu_{j \mathrm{o}} \cdot Q_{\mathrm{o}}}{V}-\sum \frac{\mu_{j i} \cdot Q_{i}}{V}$

Thus, the upper equation for $(j=0,1)$ becomes:

$$
\begin{aligned}
B_{0} & =\sum \frac{\mu_{0 \mathrm{o}} \cdot Q_{\mathrm{o}}}{V}-\sum \frac{\mu_{0 i} \cdot Q_{i}}{V} \\
G_{0} & =\left(\sum \frac{\mu_{1 \mathrm{o}} \cdot Q_{\mathrm{o}}}{V}-\sum \frac{\mu_{1 i} \cdot Q_{i}}{V}\right) / \mu_{0}
\end{aligned}
$$

Using these two equations obtains the values of growth and nucleation rate parameters at steady-state operation conditions of bubble column. The hydrodynamics and mass transfer parameters in bubble column are given by the listed equations in Table 1.

\section{Solution procedure}

After mathematic modeling, the obtained equations must be solved to simulate the column. In this simulation, liquid flow rate, mole fractions, and liquid temperature at the top of column, and gas flow rate, mole fractions, and gas pressure at the bottom of column are obtained. Also, the values of growth and nucleation rate parameters at steadystate operation conditions of bubble column are obtained. Therefore, liquid physical properties can be obtained. Then the Eqs. (9), (18), (40) can be solved numerically to obtain $U_{\mathrm{g}}, U_{1}$ and $\varepsilon_{\mathrm{g}}$, respectively. Now, all of the Eqs. (5), (7), (27), (29), (31) and (41)-(48) can be solved to obtain $x^{*}, \alpha_{\mathrm{g}}$, $P(z), E, N_{\mathrm{CO}_{2}}$ and all of the hydrodynamics and mass transfer parameters except $\varepsilon_{\mathrm{g}}$, respectively. Solving the Eqs. (21)-(23) obtains no, $r$ and $S$, respectively. Now, the Eqs. (6) and (8) can be solved by the boundary conditions (24d, e) and (26d), respectively to find $N_{\mathrm{CO}_{2}}$. Finally, Eqs. (21)-(23), (38) and (39) can be solved numerically by the respective boundary conditions to find all of the unknown parameters.

\section{Results and discussion}

The results of model are compared with the experimental results that presented by Saberi et al. [5] for the bubble column reactor of Shiraz Petrochemical Complex to valid our simulator model. Figure 2 shows the sodium bicarbonate supersaturation in the length of reactor at steadystate operating condition and Fig. 3 shows the variation of the final supersaturation of sodium bicarbonate in the bottom of the column with time. Figure 4 shows the sodium bicarbonate magma density in the length of reactor at steady-state operating condition and Fig. 5 shows the variation of the final magma density of sodium bicarbonate

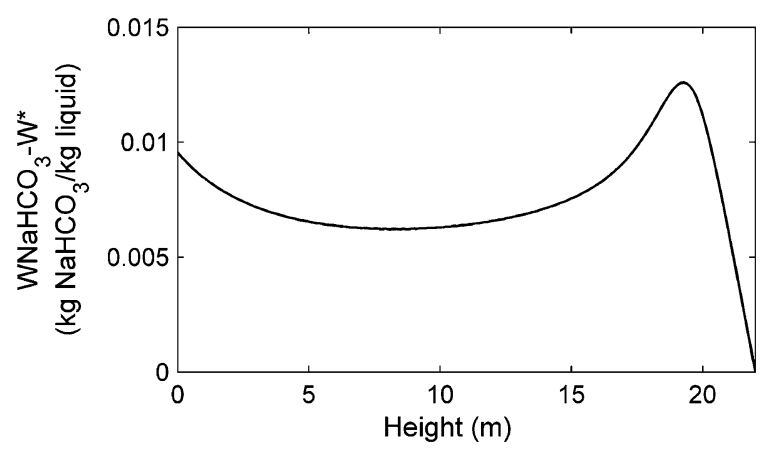

Fig. 2 Supersaturation in the length of column by simulator model

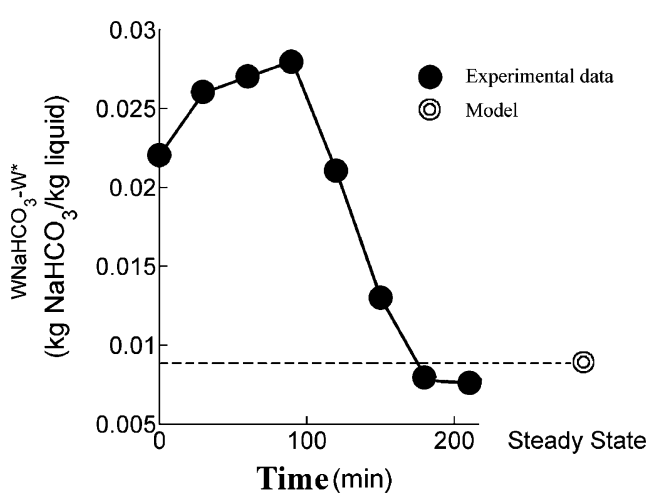

Fig. 3 Supersaturation at the bottom of column vs. time

in the bottom of the column with time. As shown in these figures, the results of model are in good agreement with the experimental data at steady-state operating conditions. Figure 6 shows the conversion of carbon dioxide in the length of column. As shown in this figure, the conversion of carbon dioxide in the top of the column is $50 \%$ which is accorded with the measured value by Saberi et al. [5]. Figure 7 shows a comparison between the predicted values of cumulative mass undersize by model in the steady-state operating condition illustrated in Fig. 1 and unsteady-state experimental data that obtained by Saberi et al. [5]. As shown in this figure there is a suitable agreement between the results of model and experimental data.

The sodium bicarbonate supersaturation in liquid phase is a function of difference of carbon dioxide (from gas phase to liquid phase) and sodium bicarbonate (from liquid phase to solid phase) fluxes. Flux of carbon dioxide is also a function of concentration of carbon dioxide in gas phase that is decreased in the length of column. Flux of sodium bicarbonate is a function of nucleation and growth of crystals that depends on supersaturation and magma density. Increasing of sodium bicarbonate supersaturation increases the flux of sodium bicarbonate. But, increasing of flux of sodium bicarbonate decreases the sodium bicarbonate supersaturation. Hence, supersaturation of sodium bicarbonate has a behavior as shown in Fig. 2. 


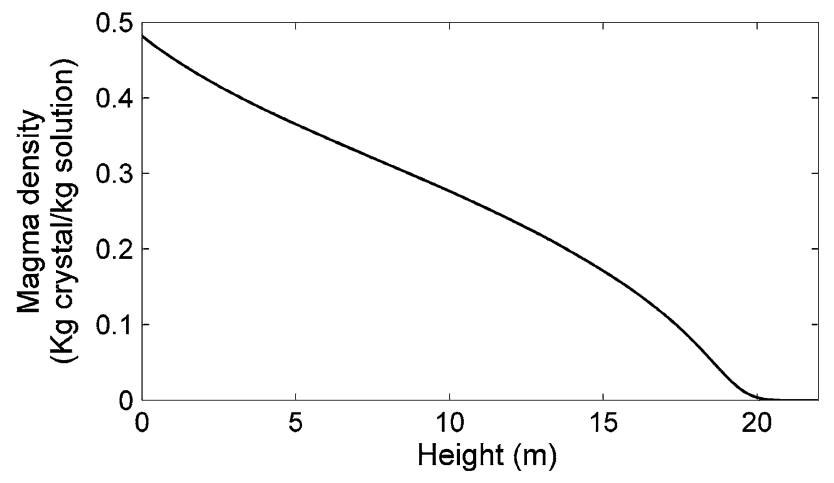

Fig. 4 Magma density in the length of column by simulator model

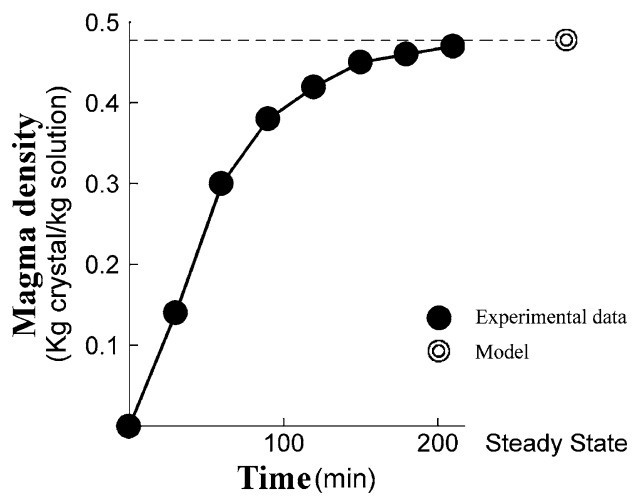

Fig. 5 Magma density at the bottom of column vs. time

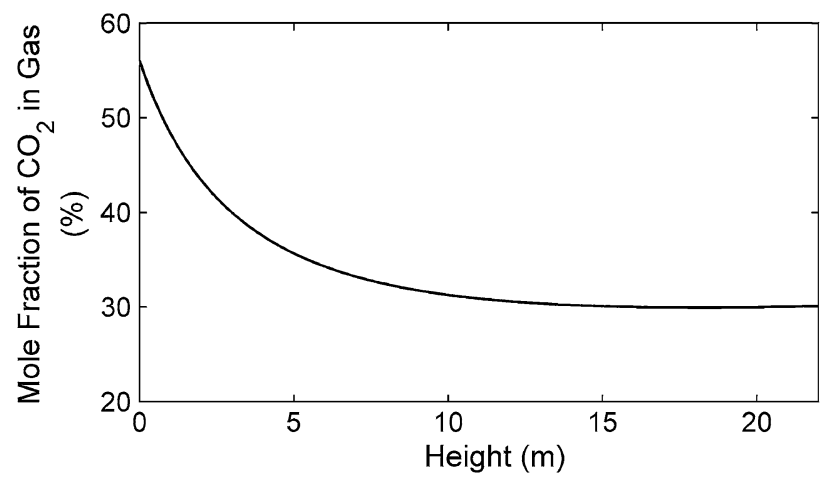

Fig. 6 Molar fraction of carbon dioxide in gas in the length of column by simulator model

Using Saberi et al. nucleation and growth formulas [5] as the first guess and mathematical methods, nucleation and growth rate for the operating conditions illustrated in Fig. 1 are obtained as following equations:

$$
\begin{aligned}
& B_{0}=26.398 \times M_{T}^{0.42} \times \Delta w^{1.31} \\
& G_{0}=1.333 \times 10^{-4} \times \Delta w^{1.53} .
\end{aligned}
$$

These two equations are too similar to the obtained experimental formulas by Saberi et al. $\left(B_{0}=26.685 \times\right.$

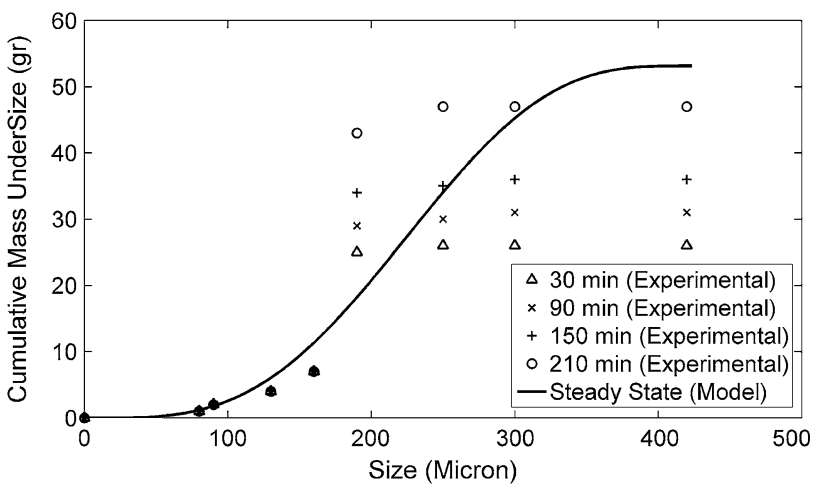

Fig. 7 Cumulative mass undersize at the bottom of column

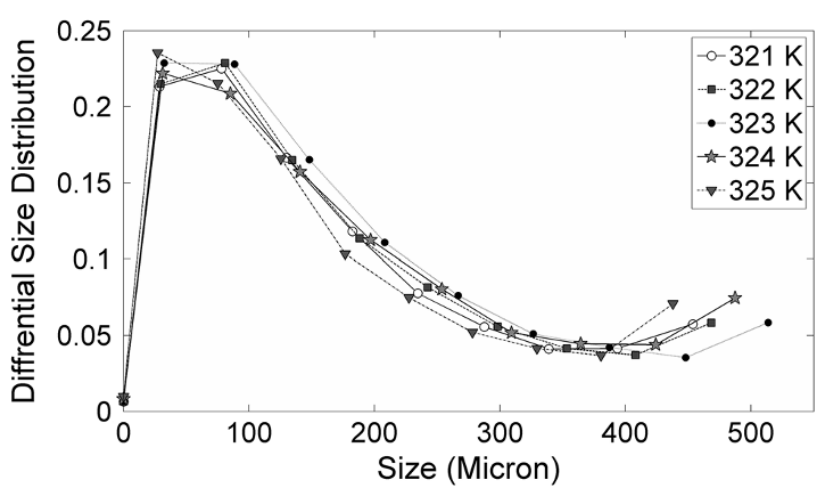

Fig. 8 Predicted produced sodium bicarbonate crystals size distribution in different liquid temperatures

Table 2 The optimized values of the kinetic parameters of sodium bicarbonate precipitation

\begin{tabular}{lrlllll}
\hline & & $a \times 10^{4}$ & $b$ & $c$ & $d$ & $e$ \\
\hline Liquid temperature $(K)$ & 322 & 1.295 & 1.53 & 22.437 & 0.42 & 1.31 \\
& 324 & 1.384 & 1.53 & 33.09 & 0.42 & 1.31 \\
Inlet gas pressure (atm) & 2 & 1.346 & 1.53 & 27.557 & 0.42 & 1.31 \\
& 3 & 1.073 & 1.53 & 19.946 & 0.42 & 1.31 \\
Inlet carbon dioxide mole & 50 & 1.344 & 1.53 & 28.026 & 0.42 & 1.31 \\
$\quad$ fraction (\%) & 60 & 1.266 & 1.53 & 22.585 & 0.42 & 1.31 \\
& & & & &
\end{tabular}

$\left.M_{T}^{0.42} \times \Delta w^{1.31}, G_{0}=1.381 \times 10^{-4} \times \Delta w^{1.53}\right)$ [5]. It is a validation for our model. It is mentioned that the supersaturation of sodium bicarbonate has a complex self dependency. Increasing of supersaturation increases the rate of nucleation and growth rate. Increasing of crystal production decays the liquid supersaturation. A change in the operating conditions can change the liquid supersaturation and also changes this complex dependency of nucleation and growth rate to the liquid supersaturation. Therefore, the nucleation and growth rate are different functions of liquid supersaturation for different operating conditions. For other different operating conditions the fitted constants of Eqs. (32) and (33) are listed in Table 2. 


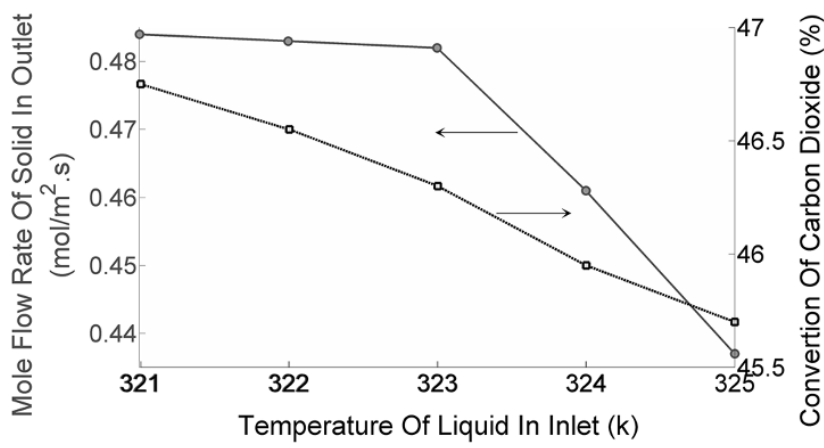

Fig. 9 Predicted percent of carbon dioxide conversion and magma density of sodium bicarbonate crystals in different liquid temperatures

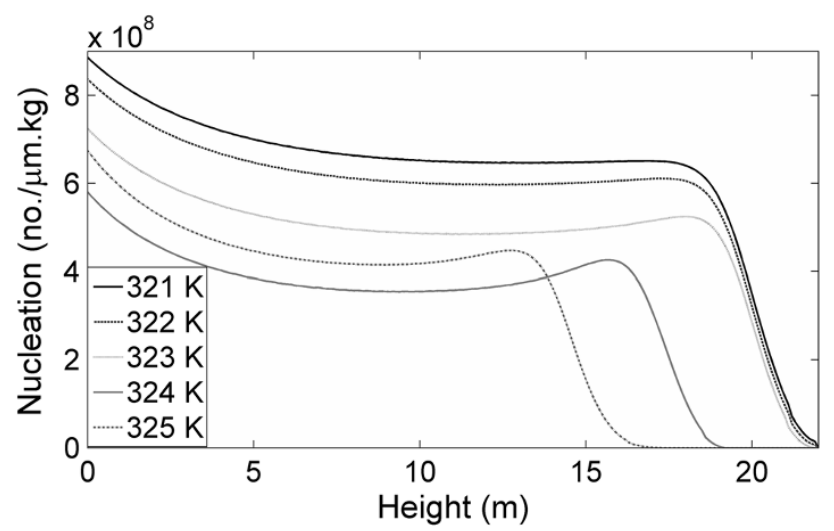

Fig. 10 Nucleation of sodium bicarbonate crystals in the length of column at different temperature

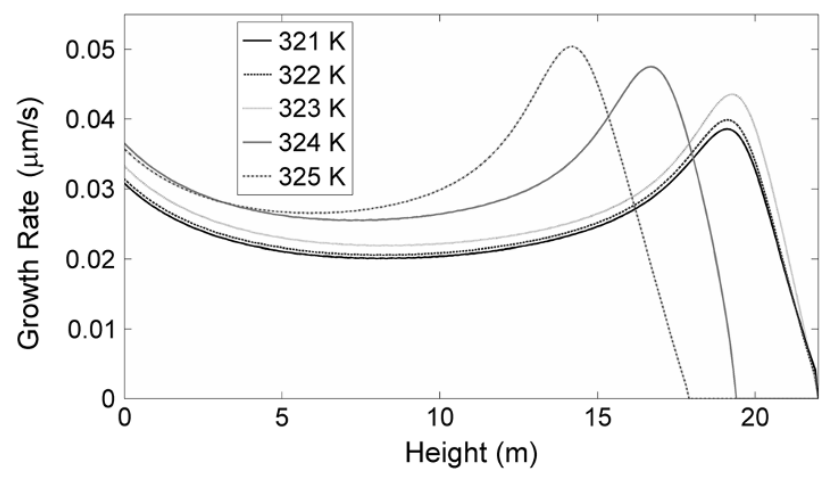

Fig. 11 Growth rate of sodium bicarbonate crystals in the length of column at different temperature

\section{Effect of liquid temperature}

Figure 8 shows the predicted produced sodium bicarbonate crystals size distribution in different liquid temperatures. As shown in this figure, increasing of liquid temperature from 321 to $323 \mathrm{~K}$ increases the maximum size of crystals. In the temperature range from 323 to 325 , this effect is reversed. But the maximum size of crystals is increased in

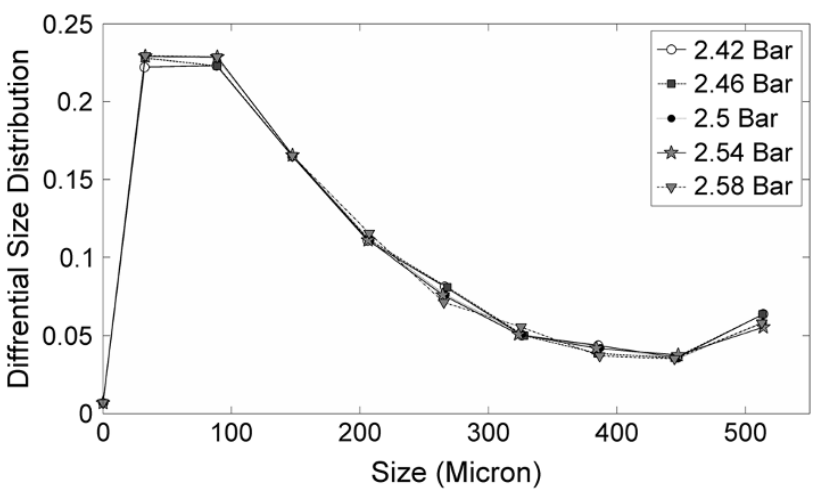

Fig. 12 Predicted produced sodium bicarbonate crystals size distribution in different gas pressures

this range of temperature. Cause of this effect of temperature is complex. Increasing of liquid temperature increases the production rate of $\mathrm{NaHCO}_{3}$ by increasing the rate of reactions (1-4), and also increases the solubility of $\mathrm{NaHCO}_{3}$ in water by attention to Eq. (5).

Figure 9 shows the predicted percent of carbon dioxide conversion and magma density of sodium bicarbonate crystals in different liquid temperatures. It is seen that the carbon dioxide conversion and also the magma density of sodium bicarbonate crystals are decreased with increasing liquid temperature. The reason is increasing of the reaction rate and therefore more carbon dioxide consumption with increasing temperature. It must be noted that increasing of the rate of sodium bicarbonate disintegration which increases the disposing of carbon dioxide could not amend this carbon dioxide decrement when liquid temperature is increased.

Figures 10 and 11 show the nucleation and growth rate of sodium bicarbonate crystals in the length of column at different temperatures, respectively. As shown in these figures, temperature has an important effect on the nucleation and growth rate of crystals. More liquid temperature causes more liquid supersaturation by increasing the reaction rate and also $\mathrm{NaHCO}_{3}$ disintegration. Increasing of liquid supersaturation increases the nucleation and growth rate of crystallization, as mentioned in the Eqs. (32) and (33). Since, production of solid crystals consumes the sodium bicarbonate of the liquid phase, increasing of the nucleation and growth rate decay amount of supersaturation of this phase. Therefore, amount of supersaturation affects self, indirectly. This is the cause of different trends in the liquid temperature 324 and $325 \mathrm{~K}$, as seen in Figs. 10 and 11.

\section{Effect of gas pressure}

Figure 12 shows the crystals size distribution of predicted produced sodium bicarbonate in different gas pressures. 


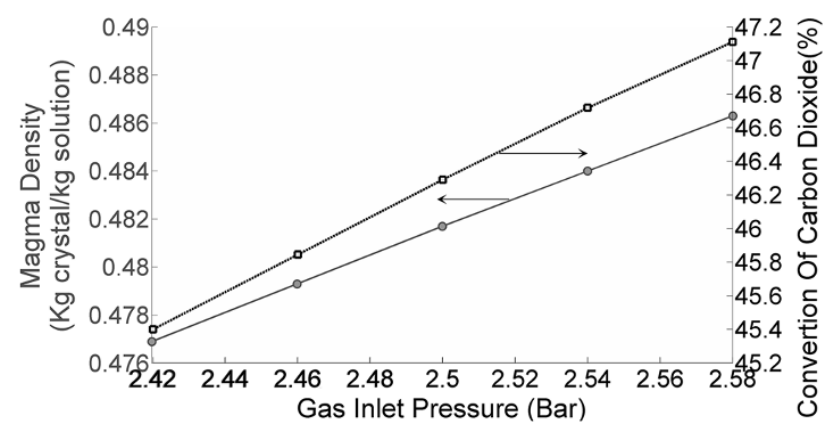

Fig. 13 Predicted percent of carbon dioxide conversion and magma density of sodium bicarbonate crystals in different gas pressures

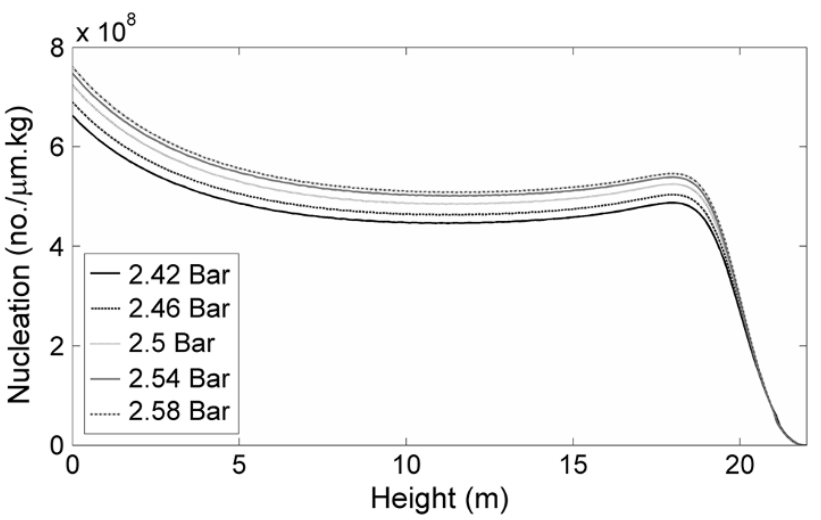

Fig. 14 Nucleation of sodium bicarbonate crystals in the length of column at different gas inlet pressure

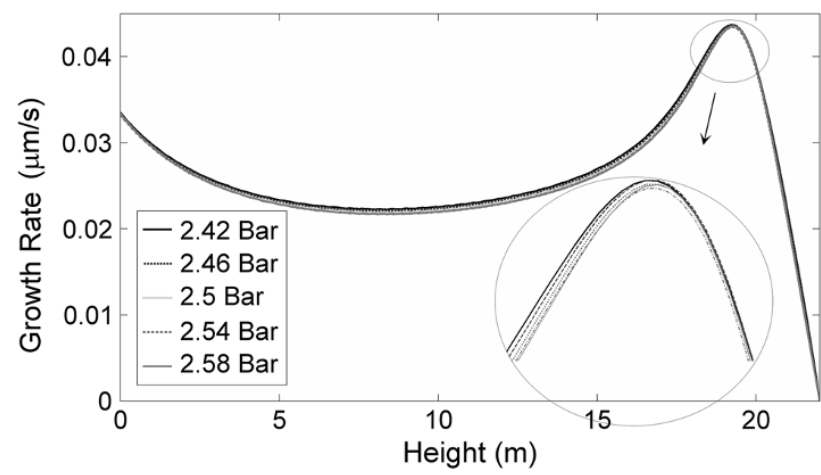

Fig. 15 Growth rate of sodium bicarbonate crystals in the length of column at different gas inlet pressure

Increasing of gas pressure decreases the size of bubbles and increases the number of them. More bubbles have a more gas-liquid interface, but cause a more mixing in the liquid phase. These two factors counteract each other in the crystal production. Therefore, increasing of the gas pressure has no significant effect on the crystals size distribution, as shown in this figure.

Figure 13 shows the predicted percent of carbon dioxide conversion and also magma density of sodium bicarbonate

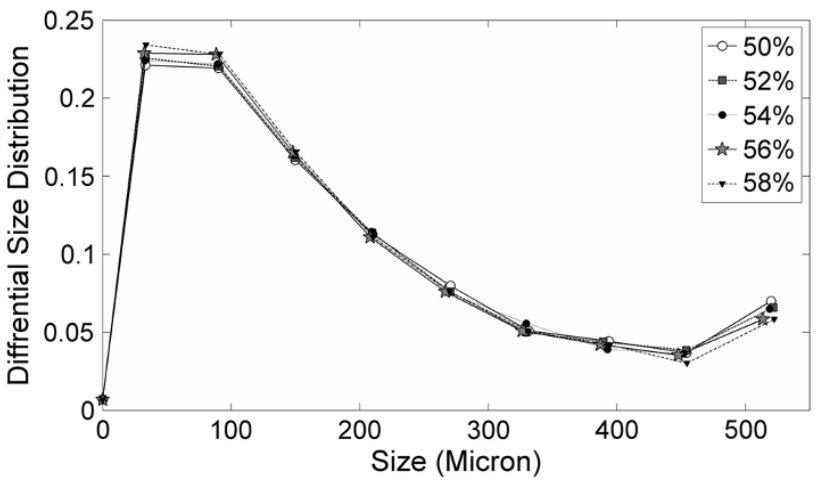

Fig. 16 Predicted produced sodium bicarbonate crystals size distribution in different carbon dioxide mole fractions

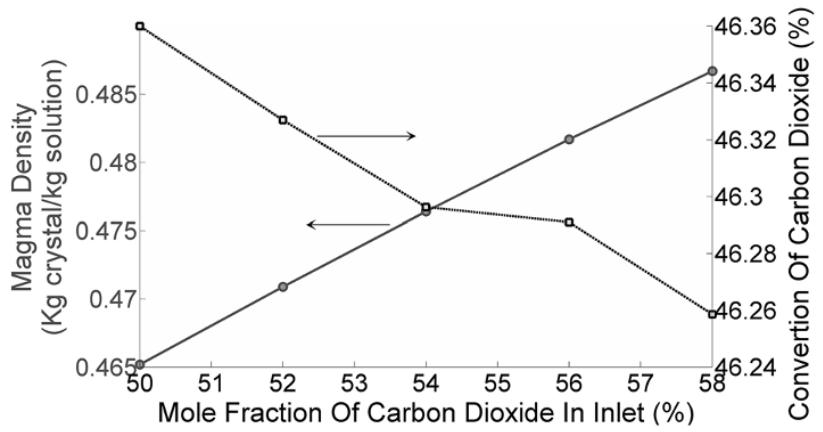

Fig. 17 Predicted percent of carbon dioxide conversion and magma density of sodium bicarbonate crystals in different carbon dioxide mole fractions

crystals in different gas pressures. This figure shows that the percent of carbon dioxide conversion and also mole flow rate of sodium bicarbonate crystals are increased with increasing gas pressure. Gas density is increased and bubbles size is decreased by increasing gas pressure. These are the cause of increasing the carbon dioxide conversion and also production rate of sodium bicarbonate crystals.

Figures 14 and 15 show the nucleation and growth rate of sodium bicarbonate crystals in the length of column at different gas inlet pressure, respectively. As shown in these figures, increasing of the inlet gas pressure increases nucleation, but has no effect on the growth rate of crystals. More gas-liquid interface and more mixing in the liquid phase are the causes of these effects on the nucleation and growth rate of crystals, respectively.

Effect of carbon dioxide mole fraction

Figure 16 shows the predicted produced sodium bicarbonate crystals size distribution in different mole fraction of carbon dioxide in the gas phase. Increasing of carbon dioxide mole fraction in the gas phase has no significant effect on the crystals size distribution, as shown in this figure. Increasing of carbon dioxide flow rate increases the 


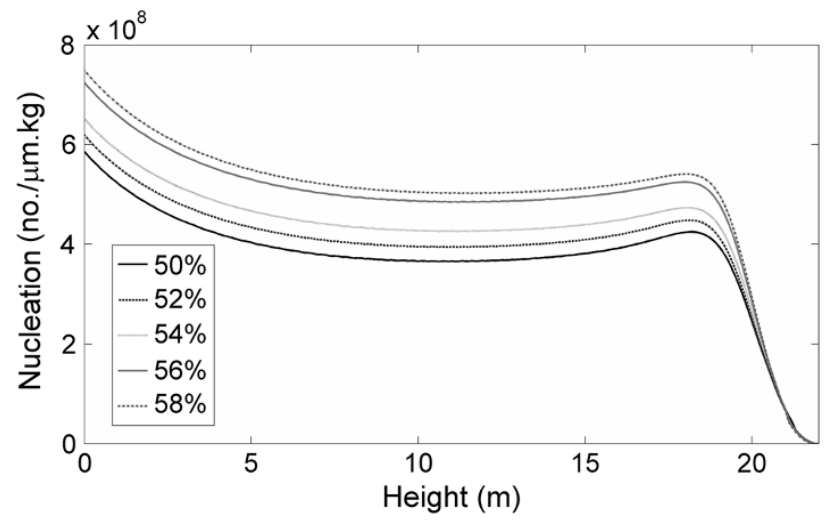

Fig. 18 Nucleation of sodium bicarbonate crystals in the length of column at different carbon dioxide mole fractions

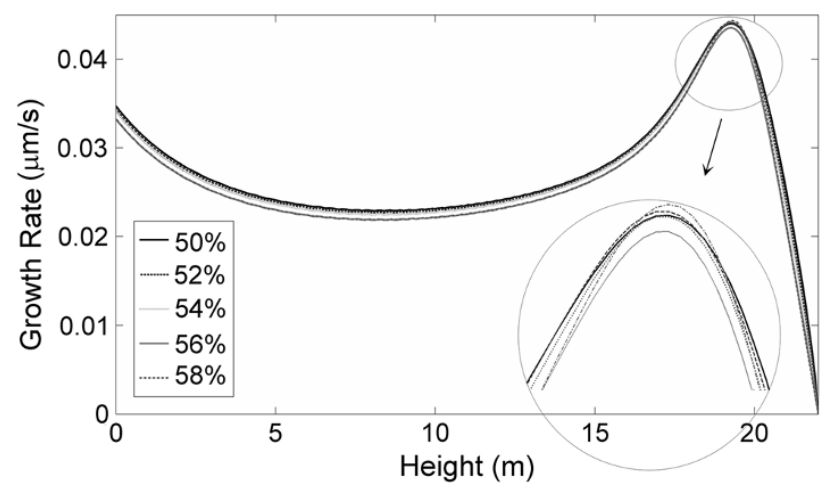

Fig. 19 Growth rate of sodium bicarbonate crystals in the length of column at different carbon dioxide mole fractions

bubbles size and decreases the number of bubbles which decreases the gas-liquid interface. On the other hand, this increment decays mixing of liquid phase. These two factors counteract each other in the crystal production.

Figure 17 shows the predicted percent of carbon dioxide conversion and also magma density of sodium bicarbonate crystals in different carbon dioxide mole fractions. As shown in this figure, the percent of carbon dioxide conversion is decreased but mole flow rate of sodium bicarbonate crystals is increased with increasing mole fraction of carbon dioxide in the gas phase. Increasing of the amount of carbon dioxide in the gas phase increases the production of sodium bicarbonate crystals. Decreasing of the gas-liquid interface decreases the rate of carbon dioxide transfer from gas phase to liquid, therefore, decreases the conversion of this component in the gas phase.

Figures 18 and 19 show nucleation and growth rate of sodium bicarbonate crystals in the length of column at different carbon dioxide mole fractions, respectively. As shown in these figures, inlet carbon dioxide mole fraction increases nucleation, but has no significant effect on the growth rate of crystals. The complex behavior of supersaturation is the cause of these effects on the nucleation and growth rate of crystals.

\section{Conclusion}

Results of mathematical simulation of bubble column show that, there are optimized operating conditions for a suitable crystal size distribution, or more carbon dioxide conversion and produce sodium bicarbonate crystals. The percent of carbon dioxide conversion and also mole flow rate of sodium bicarbonate crystals are decreased with increasing of liquid temperature and decreasing of gas pressure. The percent of carbon dioxide conversion is decreased but mole flow rate of sodium bicarbonate crystals is increased with increasing of mole fraction of carbon dioxide in gas phase. The nucleation and growth rate of crystals are changed at different operating condition, and there are different formulas at different temperatures, especially. Finally, the model results are compared with experimental results. This comparison confirms the accuracy of our model for simulating the sodium bicarbonate bubble columns.

Open Access This article is distributed under the terms of the Creative Commons Attribution License which permits any use, distribution, and reproduction in any medium, provided the original author(s) and the source are credited.

\section{References}

1. Benadda B, Prost M, Ismaily S, Bressat R, Otterbein M (1994) Validation of the gas-lift capillary bubble column as a simulation device for a reactor by the study of $\mathrm{CO}_{2}$ absorption in $\mathrm{Na}_{2} \mathrm{CO}_{3} /$ $\mathrm{NaHCO}_{3}$ solutions. Chem Eng Proc 33:55-59

2. Danckwerts PV (1970) Gas-liquid reactions. McGraw-Hill, New York

3. Haut B, Halloin V, Cartage T, Cockx A (2004) Production of sodium bicarbonate in industrial bubble columns. Chem Eng Sci 59:5687-5694

4. Soltani Goharrizi A, Abolpour B (2012) Estimation of sodium bicarbonate crystal size distributions in a steady-state bubble column reactor. Res Chem Intermed 38(7):1389-1401

5. Saberi A, Soltani Goharrizi A, Ghader S (2009) Precipitation kinetics of sodium bicarbonate in an industrial bubble column crystallizer. Cryst Res Technol 44(2):159-166

6. Hou TP (1942) Manufacture of soda, 2nd edn. Reinhold, New York

7. Broul M, Nyvlt J, Sohnel O (1981) Solubility in inorganic two component system. Elsevier, New York

8. Joshi JB, Sharma MM (1979) A circulation cell model for bubble columns. Trans Inst Chem Eng 57:244-251

9. Wylock CE, Colinet P, Cartage T, Haut B (2008) Coupling between mass transfer and chemical reactions during the absorption of $\mathrm{CO}_{2}$ in a $\mathrm{NaHCO}_{3}-\mathrm{Na}_{2} \mathrm{CO}_{3}$ brine: experimental and theoretical study. Int J Chem React Eng 6:A4

10. Randolph AD, Larson MA (1988) Theory of particulate processes. Academic Press, New York 
11. Tavare NS (1995) Industrial crystallization: process simulation, analysis and design. Plenum press, New York

12. Akita K, Yoshida F (1973) Gas hold-up and volumetric mass transfer coefficient in bubble columns. Ind Eng Chem Proc Des Dev 12:76-80

13. Pavlica RT, Olson JH (1970) Unified design method for continuous contact mass transfer operations. Ind Eng Chem 62:45-58

14. Wendt R, Steiff A, Weinspach PM (1983) Fiussigphasenruck Vermischung In Blasen Saulen-Reaktoren. Chemie-ingenieurtechnik 55:796-797

15. Akita K, Yoshida F (1974) Bubble size, interfacial area, and liquid mass transfer coefficient in bubble columns. Ind Eng Chem Proc Des Dev 12:84-91
16. Danckwerts PV, Sharma MM (1966) The absorption of carbon dioxide into solutions of alkalis and amines. Chem Eng 44:244-280

17. Tamimi A, Rinker EB, Sandall OC (1994) Diffusion coefficient for hydrogen sulfide, carbon dioxide, and nitrous oxide in water over the temperature range 293-368 K. J Chem Eng Data 39(2):396-398

18. Gallagher PK, Brown ME, Kemp RB (1998) Handbook of thermal analysis and calorimetry. Elsevier, New York 